Provided for non-commercial research and education use. Not for reproduction, distribution or commercial use.

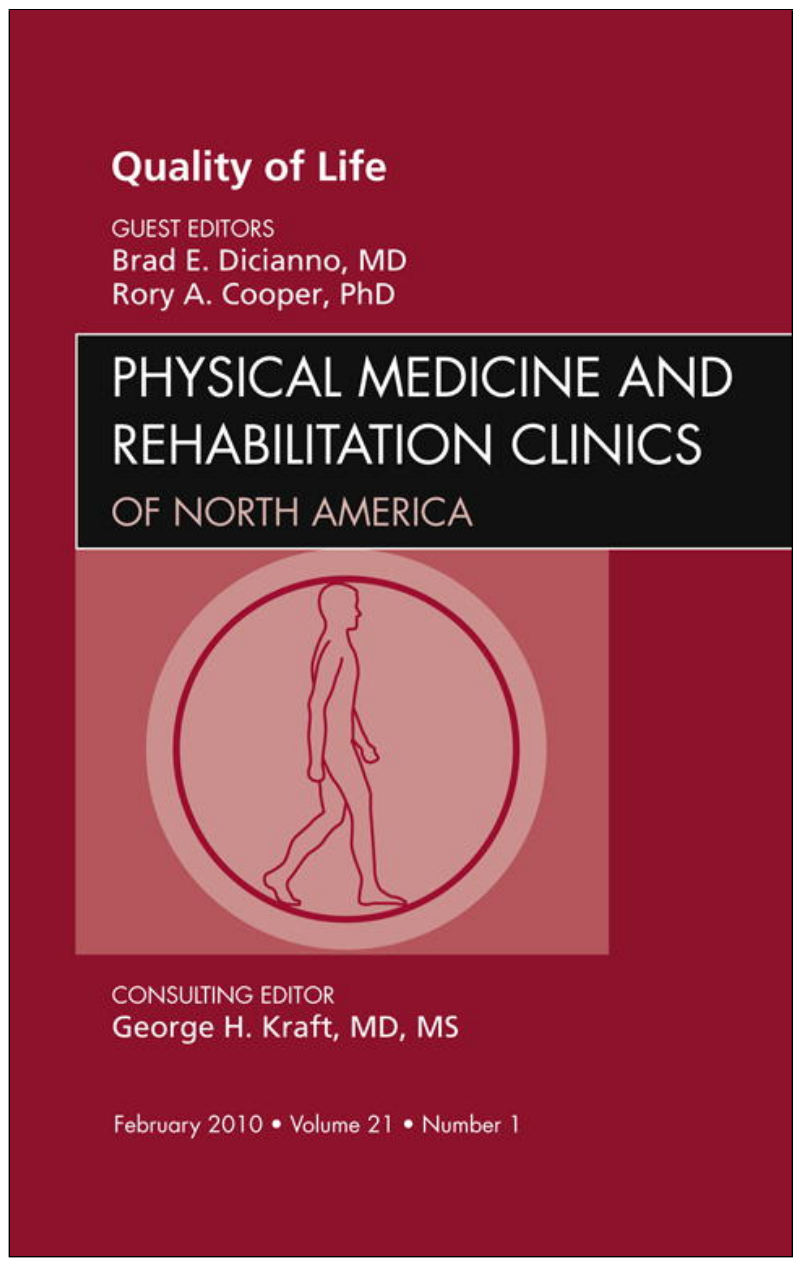

This article appeared in a journal published by Elsevier. The attached copy is furnished to the author for internal non-commercial research and education use, including for instruction at the authors institution and sharing with colleagues.

Other uses, including reproduction and distribution, or selling or licensing copies, or posting to personal, institutional or third party websites are prohibited.

In most cases authors are permitted to post their version of the article (e.g. in Word or Tex form) to their personal website or institutional repository. Authors requiring further information regarding Elsevier's archiving and manuscript policies are encouraged to visit:

http://www.elsevier.com/copyright 


\section{Quality of Life \\ Technology: \\ The State of Personal \\ Transportation}

Linda van Roosmalen, $\mathrm{PhD}^{\mathrm{a}, *}$, Gregory J. Paquin, $\mathrm{BSC}^{\mathrm{b}}$, Aaron M. Steinfeld, $\mathrm{PhD}^{\mathrm{C}}$

\section{KEYWORDS}

- Transportation • Safety $\bullet$ Independence $\bullet$ Wheelchair

- Driving • Controls

For most of the United States population, community participation and basic activities of daily living depend on access to personal vehicular transportation. This culture of "automobility" is likely to continue, and it seems that older persons will need to drive more in the future. ${ }^{2}$ This trend is complicated by license loss among older drivers. The total drop in licenses among individuals between ages 60 and 84 years, for reasons other than death, was 1.8 million in $2000 .^{3,4}$

As with the aging population, a related trend is seen in wheeled mobility use (eg, wheelchairs, scooters). In the past 30 years, a sixfold increase of wheeled mobility users has occurred among the United States population, and the total number is expected to reach 4.3 million by $2010 .{ }^{5}$ Particularly relevant is that this "growth far exceeds the growth in the older population." 5 (p. 15)

Among individuals within this population, approximately a quarter drive and almost a third do not live in areas with public transit services. The Americans with Disabilities Act (ADA) requires that public transportation vehicles be accessible to the public, and requires demand responsive systems to be in place to serve individuals who have disabilities who are unable to use regular public transportation. ${ }^{6}$ Lack of access to

\footnotetext{
Work presented in this manuscript is partially supported by Grant No. H133E060064 from the Department of Education and the National Institutes for Disability and Rehabilitation Research and the National Science Foundation under Grant No. EEC-0540865 and Grant No. EEC-0552351.

a Department of Rehabilitation Science and Technology, University of Pittsburgh, 2310 Jane Street, Suite 1300, Pittsburgh, PA 15203, USA

b California Department of Rehabilitation, 9720 South Norwalk Boulevard, Santa Fe Spring, CA 90670, USA

' Robotics Institute, Carnegie Mellon University, 5000 Forbes Avenue, Pittsburgh, PA 15213, USA

* Corresponding author.

E-mail address: Lvanroos@pitt.edu (L. van Roosmalen).
} 
transportation is one of the most frequently cited problems for rural residents. ${ }^{7}$ For individuals who have mobility limitations living in remote areas or areas that are not along the route of fixed route transit services, special arrangements must be made, such as with para transit services for which eligibility criteria exist.

For all individuals, including those who have disabilities and those who are elderly, access to the community is important for employment, socialization, health services, and the operation of households and businesses. A study by Gray and colleagues ${ }^{8,9}$ indicates that transportation is a key barrier to community participation among individuals who have disabilities. The infrastructure in the United States is built around the widespread use of motor vehicles and public transportation systems. These include commuter rail systems and metro, fixed, and demand route transportation services that are commonly in place for those who cannot afford, are unable to operate, or choose not to use a personal motor vehicle. Projects are underway to produce autonomous vehicle that can drive themselves. Until these technologies are perfected, persons who have disabilities choosing to drive themselves in a personal vehicle will have to rely on their own abilities to control a vehicle.

Equipment and modifications currently available allow vehicle drivers to compensate for many physical limitations. Devices to assist disabled drivers have steadily improved since the time of President Roosevelt.

As with all changes in technology, the ability to produce and profit from sales of devices is paramount. The driving mobility industry is unique in that the volume of sales is significantly low, causing small businesses to be the major developing sector of the industry and resulting in the development of product concepts that only address a particular functional disability. The device or product to support the device may have worked well, but a change in the way a disability is treated, new materials to lessen the weight of a product, the availability of colors, or other technology changes may have made some company's product undesirable.

\section{PRACTICES TO PROMOTE SAFE AND INDEPENDENT DRIVING Clinical Considerations in Driving}

In the United States, approximately 11,000 individuals experience a new spinal cord injury (SCl) per year and have varying numbers of disabilities from stroke, muscular dystrophy, ataxia, spina bifida, amputations, reduced upper extremities (traumatic and congenital absence), amyotropic lateral sclerosis (ALS), multiple sclerosis, spinal muscular atrophy, polio, arthrogryposis, osteogenesis imperfecta, rheumatoid arthritis, and various other illnesses. ${ }^{10,11}$

Each injury, ailment, disease, or disorder has a unique set of motor, sensory, and cognitive issues to be addressed for the person to be considered a safe and independent driver. Each condition may have some expected limitation, but the degree of disability generally varies among individuals. ${ }^{12}$ For example, the difference in physical ability of a person who has an $\mathrm{SCl}$ can vary significantly depending on the level and complexity of the injury. Further complications can arise if the event that caused the $\mathrm{SCl}$ created a secondary effect through a traumatic brain injury (TBI). This impairment may not be noticed until the interactive cognitive skills of driving are required. ${ }^{13}$

The question that must be answered for any potential driver (teen/adult/mature) during a clinical evaluation is whether the driver processes pertinent, environmental traffic information in a timely manner, and executes appropriate and timely responses based on the perceptions of situations encountered. The best person to answer this question is a trained and Certified Driver Rehabilitation Specialist (CDRS). A CDRS is knowledgeable in the selection, use, and application of devices and methods to 
aid drivers who have disabilities. An unbiased perspective about what type of equipment will work best for a driver can have a huge impact on driver safety, the longevity of their driving career, the cost of the modifications, and the ability to maintain the equipment.

The paths to obtain a referral to a driving evaluation can vary. If the potential driver is a private payer, the vehicle modifier would recommend a local driver evaluation program. If a third-party payer is involved, the CDRS would recommend a driver evaluation program; if the third party is a government entity, the CDRS may have an evaluation program or a contract within one. Various government agencies, such as Veterans Administration, State offices of Vocational Rehabilitation, Workers Compensation Fund, Victims of Crime, Department of Aging, and other health-related departments, may help provide funding for the driver evaluation.

Often a team approach is used to best understand all the details involved in determining the appropriate equipment and training for a safe and independent driver. An occupational therapist will establish the physical and cognitive baseline of a potential driver and a driving instructor will safely guide the driver through basic vehicle functions and an on-the-road evaluation. A rehabilitation engineer will provide equipment and methods for the driver to compensate for any physical limitations. All team members may participate in each portion of the evaluation and in the selection of appropriate assistive driving devices, and in some cases these roles are performed by the same individual.

Most clinicians involved with driving assessments, equipment selection, and driver evaluations are members of the Association for Driver Rehabilitation Specialists (ADED). ${ }^{14}$ In 2008, the ADED had approximately 576 members, of which 229 were CDRSs. ${ }^{14}$ This number is small compared with the increased need for services to enable older individuals and those who have disabilities to drive. As part of the Quality of Life Technology Engineering Research Center Safe Driving Project, the University of South Florida and University of Pittsburgh are currently evaluating the use of a driving simulator to train individuals who have disabilities to use adaptive driving equipment in a simulated driving environment. Driving simulators have potential to assist in driving assessments because of their relatively low cost, ability to track driver learning, and ability to make instrumentation adjustments on the fly. Obviously, actual road driving remains a key component in the assessment process and when learning safe driving in the community. ${ }^{14}$

\section{Functional Abilities}

A battery of tests and assessments are administered to create a baseline from which the CDRS team can appraise safe driving potential. These tests do not necessarily conclude the client's driving potential; they establish which functional abilities the person has and the limitations that could pose a problem when driving. The client's ability to compensate for any deficit while behind the wheel is the true test of a driver's potential. ${ }^{15}$ The standardized and nonstandardized tests and assessments to determine safe driving potential address the following factors ${ }^{16}$ :

- Vision and perception: The client is administered standardized test to determine visual acuity and visual fields, color vision, depth perception, contrast sensitivity, processing time, visual tracking, and the ability to multitask. These tests help determine how well the client sees objects and if their perception of the location is correct.

- Strength and range of motion: Physical characteristics of the client are measured. For each limb, strength and active range of motion are determined for the ability to operate the primary controls of the vehicle. Head rotation for scanning traffic is 
observed and documented. Other areas assessed include joint restrictions in neck and limbs, motor control, dexterity, and balance.

- Reaction time to determine eye-limb coordination: Several tests are given to gather information on the potential driver's ability to process visual information and react to it properly. Characteristics about the client's disability are noted to determine factors such as the progressive nature of the disability and if it will impact the choice of driving equipment.

- Cognitive issues and confidence: Other tests will provide information about the potential driver's understanding of road signs, ability to engage in more complex driving situations, and ability to multitask. Areas observed include memory, visual processing, visual perception, visual special skills, selective and divided attention, and executive skills.

- Driving assessment process: Once the clinical details of the driver have been established, the evaluation progresses to the vehicle assessment. Access to the vehicle is investigated, ranging from whether the driver is able to transfer from the outside of the vehicle to the driver seat, to how the driver adjusts to sitting in the wheelchair at the driver station. Numerous arrangements and adjustments within these extremes dictate the final scenario for access. Once access has been established and safety systems are in place (shoulder/lap belt), the driving controls are considered. The dominant hand is usually chosen for steering, but this may deviate if other factors or equipment are presented.

- Driver evaluation: The potential driver is progressively given control of the vehicle. Depending on the situation, the CDRS or driving instructor may begin with the client steering in a safe environment, such as a parking lot. Eventually, the evaluation will progress to have the client also operate the gas/brake controls. They will gradually proceed onto the streets and then to even greater traffic interaction. The potential driver will be exposed to turns, controlled intersections, light and heavy traffic, and confusing situations to test their ability to respond appropriately.

- Flexibility to test suspected capabilities: Occasionally the CDRS or driving instructor may observe a characteristic of the potential driver that indicates a lacking driving skill or a cognitive limitation. This deficiency may be the result of the client being a new driver with little experience on the road, or could indicate a larger issue that will require substantial understanding of the client's disability and the mobility equipment used to compensate for the disability.

- Endurance issues: Persons who have certain disabilities frequently have limitations caused by fatigue (eg, from muscular dystrophy, multiple sclerosis, or post-polio syndrome). A CDRS and driving instructor who understand a person's disability can observe if the driver is showing signs of tiredness or lack of concentration from fatigue or extreme temperature changes. Startle responses can also impact the client's safe driving and also should be evaluated, for example by traversing rumble strips and speed bumps.

\section{VEHICLE SELECTION AND MODIFICATION}

Vehicle modifications should preferably be done by vehicle modifiers who follow guidelines established by the National Mobility Equipment Dealers Association (NMEDA). ${ }^{12}$ This organization is dedicated to broadening the opportunities for people who have disabilities to drive or be transported in vehicles modified with mobility equipment. ${ }^{12}$ Many vehicles are available to drivers who have disabilities, and the array of types and sizes of cars and vans is almost unlimited. When minivans and full size vans are modified with a lowered floor, the accessibility to vehicles for a wheelchair user has 
an even greater application. Although the main purpose of lowering the minivan floor is to position the eyes of a driver in a wheelchair at the correct height relative to the windshield, another benefit is that an access ramp can be at a lesser slope for ease of ingress.

Depending on whether the driver uses a wheelchair and the type of vehicle (sedan, SUV, truck, van, or minivan) there are several ways and assistive technologies available to help individuals who have disabilities enter and exit the vehicle. For individuals who have minor limitations, a simple grab bar may be adequate. A swivel seat can be used for individuals who are unable to maintain balance while stepping into the vehicle.

When individuals are unable to independently and safely transfer from a wheelchair into a motor vehicle seat, a ramp or lift must be installed to help with boarding and exiting to allow the wheelchair to be positioned in the driver station. Ramp systems are becoming popular and are made to slide out from under the floor and fold out from the doorway.

Wheelchair lifts have been used for more than 30 years and have drastically changed the mobility of individuals who have disabilities, allowing wheelchair users to be independent and mobile. The impact of mobility on a person's well-being, including the ability to get out and about, interact with the community, and be gainfully employed are some of the major desires of a complete life and should not be underestimated. As one wheelchair lift customer in 1979 stated, "Without what you do...I wouldn't have a life."

Major changes have occurred recently in the national standards applied to the manufacturing and installation of wheelchair lifts for individual use. These changes address safety concerns by adding warning devices and vehicle interlocks to prevent the lift from improper and unsafe use. ${ }^{17,18}$ Wheelchair users may encounter space constraints in their vehicle. A transfer seat base can be used to position the original equipment manufacturer (OEM) seat at a desired location to best facilitate a transfer. The transfer seat base typically mounts to the floor in the driver location and the OEM seat is bolted to a top plate. The device allows the seat to move forward and backward, up and down, and rotate to the right through the use of control switches.

Drivers who have disabilities would dock the wheelchair behind the seat and transfer. After the transfer is complete, users would operate the switches to position the seat for driving. Some makers of transfer seat bases have successfully crash tested their product, so the OEM seat belts can be attached to the seat (B\&D Independence Inc., Mt. Carmel, Illinois). Technology developed by Freedom Sciences (Freedom Sciences LLC, Philadelphia, Pennsylvania) allows wheelchair-seated drivers to pull up to the side of the vehicle and transfer into a power seat that extends from the vehicle so that it is level with the driver's wheelchair seat. After the individual has transferred into the power seat, the wheelchair is (remotely) parked in a docking system at the back of the vehicle. This system can be useful for individuals using powered mobility devices and who have the ability to perform independent side-to-side transfers.

\section{DRIVING CONTROLS}

\section{Primary Controls}

Primary controls refer to the steering, accelerator, and brake controls of the vehicle. For a disabled driver, the wheel and pedals may need to be modified to allow for weakness or limited range of motion. The control inputs may need to be relocated to a position where they can be reached. Various interfaces are used to allow a driver to have 
a secure connection with the vehicle. These control interfaces range from a simple spinner knob, to a yoke and T-shaped device for drivers who have grip strength, to tri-pin arrangements to allow a secure hold for drivers who have minimal grip strength.

If a driver has sufficient upper-extremity range of motion and strength, they may be able to use mechanical devices to operate the gas/brake controls. Rods and levers can be positioned so the driver's hand can operate the pedals. Controls that use a motor to move the pedals are referred to as powered controls. The driver would operate a lever that would cause a motor to move the OEM pedals.

Another example of powered controls can be found in reduced-effort steering. The strength required to turn the steering wheel is generally reduced by $50 \%$ or $75 \%$, which can help a driver who lacks strength in steering. In the event of engine failure (such as caused by a fan belt coming off), the steering pump would stop providing power steering and the driver would require substantial strength to turn the steering wheel. A separate pump used for backup would turn on when it senses low hydraulic pressure in the steering system. This pump would allow steering to remain operational at reduced effort long enough for the driver to pull over to a safe location. A steering backup system is also advisable for standard power steering systems for drivers who have enough strength for the OEM power steering but not enough to turn the steering wheel when the engine is off. Most devices that reduce the force needed to operate primary controls incorporate a backup system that would allow for continued reduced effort on vehicle controls when the engine fails to operate.

New advances in vehicle controls have allowed for electronic or computer interfaces to control the steering, gas, and brake. This approach can be accomplished with a two-handed system or, at the most extreme level, a joystick input. At this "driveby-wire" stage, the operator and the vehicle have no direct link. This method incurs some degree of risk from the possibility of electrical system failure. If designed correctly, this is not as big of a concern as one might think. In fact, many commercial jets are "fly-by-wire" and have performed well. Drive-by-wire provides an opportunity to select from a wide array of control choices, including joysticks, levers, and smalldiameter rotary inputs, thus permitting custom control designs appropriate for a driver's specific needs.

This drive-by-wire technology has not been fully optimized for use in mainstream vehicles, and inherent control issues with electronic interfaces and computer controls remain. The main areas are the lag or delay in response time and the absence of sensory feedback from the road from the lack of a closed-loop system. Because of these limitations, drivers must possess above-average cognitive skills, and the training requirements to use drive-by-wire are extensive.

\section{Secondary Controls}

The primary controls are used to drive the vehicle. The secondary controls are used to manage the vehicle and interact with the elements and other drivers on the road. Operating the turn signals or shifting the transmission are some of the necessities when driving, and are examples of secondary control functions. Secondary controls are classified into three modes: A, B, and C. Turn signals, the horn, high-beam headlights, and wash/wipe functions fall into the mode $A$ control category that is used when the vehicle is moving. Mode $B$ controls can be operated when the vehicle is stopped and under driver control. Examples of mode B controls include transmission shifting, ignition, and vehicle startup. Mode $\mathrm{C}$ controls are used when the vehicle is stopped and includes the door locks, radio, hazard flashers, heater/vent/air conditioner (HVAC), light controls, mirrors, parking brake, power seats, rear accessories (defogger), and child safety window locks. Many devices are available to 
accommodate disabled drivers, and controls can be positioned to be operated by the elbow, by a free finger, by a mouth stick, or through voice input.

Early vehicle conversions used existing OEM switches, and attached levers and extensions to allow drivers to reach the secondary controls. These adaptations can still be used reliably, but the design of the newer vehicles precludes some previously used applications. Currently, individuals who have higher levels of disabilities are on the road, requiring a more sophisticated system to allow independent control of secondary vehicle functions. Operating a single switch with the touch of a finger or bump of the elbow can trigger a microcomputer to signal the driver to select a function, and a second action of the switch will operate the selected function. The system must match the driver's ability and comfort level so it can be used reliably. ${ }^{19}$

\section{WHEELCHAIRS USED AS SEATS IN MOTOR VEHICLES}

\section{Drivers Using Original Equipment Manufacturer Seating}

If a person's disability has caused a minimal loss of strength and limited range of motion in only one or two limbs, many simple methods of vehicle controls can be used. These drivers can often use the existing (OEM) vehicle seat. The seat may be accessed from the driver door or from the inside area of a van or minivan. If a mobility device is used, such as a wheelchair, scooter, crutch, or walker, the driver must stow and secure the aid in a safe location. Driving from the OEM seat is a preferred method because the seat is designed and tested to meet Federal Motor Vehicle Safety Standards (FMVSS). ${ }^{20}$ The seat also provides a stable platform to drive from and it is designed to work with the vehicle-mounted safety systems, such as the head and backrest, seatbelt system, and airbag system designed to protect drivers in the event of a motor vehicle accident.

\section{Drivers Seated in Wheelchairs}

Individuals who remain in their wheelchairs while driving can often not use the OEM seats because of their postural needs or inability to independently transfer in a safe and timely manner from their wheelchair seat onto the OEM seat surface. Because OEM seats are designed to withstand crash-level loading and are positioned to function optimally with the airbag system and the three-point safety restraint (seatbelt), individuals who stay seated in their wheelchairs are disadvantaged in several ways. First, their wheelchair may not be designed to function as a seat in a motor vehicle. Second, the occupant restraint system or seatbelt system does not always fit optimally around the driver's pelvis and upper torso because belts interfere with the wheelchair frame and armrests. Third, the airbag may be disconnected because of the selection and placement of primary vehicle controls. ${ }^{21,22}$

Furthermore, a wheelchair must have sufficient rigidity to provide a stable driving platform and have a way to be tightly secured in the driving position during normal driving conditions but also during a vehicle impact. Individuals who use a power wheelchair with tilt-in-space features may encounter additional issues when using their tilt system in the tight driver station or while driving.

Depending on the level of disability, a wheelchair-seated driver's primary control system may range from a highly sensitized to a simple mechanical lever. In a highly sensitized system, even a small movement of the secured wheelchair or seating system may translate into significant alterations in driving control positioning, causing difficulty in maintaining lane position.

When selecting a wheelchair to use as a seat in a motor vehicle, experts recommend choosing one that complies with RESNA WC4: 2009, Section 19. ${ }^{23}$ Section 19 
establishes design and performance requirements and test methods for complete wheelchairs that are used as seats in motor vehicles. Recently, RESNA WC-4: 2009, Section 20 was added to include design and performance requirements and test methods for seating systems that are designed to retrofit various wheelchair base frames. ${ }^{24}$ The so-called WC19-compliant wheelchairs feature appropriate wheelchair battery retention during vehicle impact (powered wheelchairs only), a crashworthy seat surface, four easily identifiable anchor points to secure the wheelchair with a four-point tiedown system, and an attachment point on the wheelchair frame to anchor a crash-safe wheelchair-mounted pelvic belt. ${ }^{23}$ Awareness of WC19-compliant wheelchairs among CDRSs is important for providing wheelchair-seated drivers with optimal (transit-safe) wheelchair seating while driving in a motor vehicles. ${ }^{22}$

Although a four-point belt-type tiedown system is the standard system to secure wheelchairs in motor vehicles, ${ }^{25}$ these systems are primarily designed to be used by an assistant. Wheelchair users are typically unable to independently secure their wheelchair with a four-point tiedown system. Therefore, wheelchairs used by drivers in private vehicles are commonly secured with an automated lock-down system that allows for independent and automatic docking of the wheelchair to the vehicle floor. This docking-type securement secures the wheelchair in a specific position and prevents the wheelchair from moving more than a nominal distance in and around three axes. Several wheelchair tiedown and occupant restraint (WTORS) manufacturers (EZ-Lock, Permobil, Q'Straint, and Sure-Lock) have developed docking systems and matching brackets that attach to the bottom of a wheelchair. To ensure safe driving, docking-type securement systems must be dynamically tested to meet performance criteria described in SAE J2249 and ISO-10542 standards. ${ }^{25,26}$

To minimize excessive rider movement and limit a wheelchair-seated driver from impacting driving controls, the windshield, or other interior structures, the driver must be able to use the safety belt system (shoulder and lap belt) independently. For this system to be effective, belts should fit snugly across the pelvis, chest, and shoulder. ${ }^{27-29}$ The van modifier and CDRS must communicate to make sure that the safety belt system is placed so that the wheelchair-seated driver can easily and independently enter the driver station, and that belts fit snugly across the driver's pelvis and upper torso.

Q'Straint, in collaboration with the Rehabilitation Engineering Research Center on Wheelchair Transportation Safety, is currently developing a system that provides wheelchair-seated drivers with independent and easier access to the seatbelt system. And for individuals whose armrests interfere with proper belt routing, the lap belt can be disengaged from the shoulder belt and positioned through the armrest for a more optimal fit. Easy belt positioning and proper fit are best achieved if the wheelchair chosen has an open-style armrest that allows the pelvic belt to lie close to the body for optimal positioning and fit. A closed or T-shaped armrest prevents an optimal pelvic belt fit and forces the belt over or against the armrests structure, ${ }^{22}$ allowing the lap belt to slide over the abdomen, causing internal injury during a frontal impact. ${ }^{30,31}$

If the muscles supporting the lower or upper torso are not adequate to maintain proper body position during severe driving maneuvers, additional (lateral) supports should be used, such as a chest harness, lateral stabilizers, pelvic supports, or shoulder pads. These postural supports should be used in addition to, rather than instead of, the seatbelt system because most wheelchair-mounted belts have not been crash tested and some are even designed to break away from the wheelchair during a vehicle crash.

Research further indicates that wheelchair-seated drivers are often positioned close to the steering wheel to reach the vehicle's adaptive equipment. ${ }^{21,22}$ In vehicle 
accidents in which the air bag deploys, severe injuries can occur, especially if the driver is not using a properly positioned seatbelt system. The National Highway Traffic Safety Administration, which sets standards for motor vehicles, allows certain exemptions and alterations to air bags for vehicles used by disabled drivers. Air bags may be disconnected depending on the make and model of the vehicle. However, when disconnecting or removing an airbag, the driver should use a well-fitted and wellpositioned safety belt for protection.

Finally, OEM vehicle seats are equipped with a headrest to limit head movement, reducing the risk for neck injury during frontal and rear impact. ${ }^{32-34}$ Guidelines for using postural support devices by wheelchair users during motor vehicle travel state that excessive rearward head and neck movement can be reduced with a wheelchair-mounted headrest. Although headrests may not be designed to withstand crash-level loading, ${ }^{35-37}$ they can provide partial protection (against whiplash) if positioned close to the back of the head. ${ }^{38}$

\section{SAFETY AND INFORMATION SYSTEMS}

Risk for occupant injury can be directly minimized through the use of safety and informational systems onboard a vehicle. Several technologies are on the market and the horizon for individuals who have disabilities and those who are elderly to help them drive safely.

\section{Navigation}

For drivers who do not have difficulty with divided attention, the value of in-vehicle navigation may be an important feature because of reductions in confidence or ability to navigate in unfamiliar territory. If drivers acknowledge this difficulty, they only drive on familiar routes. Thus, in-vehicle navigation systems are becoming attractive to drivers as a means to compensate for poor or impaired way-finding abilities. This interest includes nondisabled drivers in a new or confusing area who are impaired by the unfamiliarity of the environment.

\section{Collision Warning Systems}

Collision warning systems (CWS) warn for potential collisions and have obvious benefit in the form of early warnings for drivers who have difficulty perceiving the road scene or have slow response times. The desire to reduce rear-end crashes is the motivation for these systems, because approximately $30 \%$ of all crashes, injuries, and property damage are of this type. ${ }^{39} \mathrm{CWS}$ and blind-spot detectors have been on the market but have mostly been installed on commercial vehicles, such as tractortrailers.

Blind-spot detectors can benefit individuals who have limited head or neck range of motion. Most sensors only watch ahead of the car, but some include side-looking presence sensors to help with lane change maneuvers. Research systems capable of more complex side warning have been tested, ${ }^{40}$ but these are far from getting to market because of the difficulty of tracking vehicles in two dimensions. In all of these cases, a user interface indicates to the driver when a collision is imminent, thus prompting corrective action by the driver.

\section{Adaptive Cruise Control}

When CWS is tied to the automobile's cruise control, the vehicle can automatically respond to front obstacles by releasing the accelerator, shifting to a lower gear, or activating the brakes. This system is referred to as adaptive cruise control (ACC). 
This feature has the potential to help drivers who have a tendency to stop too late or have trouble maintaining an appropriate following distance. Currently, ACC is an option on some luxury cars and is available in some modern commercial trucks. Most of these systems are designed for highway speeds but systems are also available that operate all the way down to stop-and-go traffic. Although CWS and ACC will likely improve safety for the general public, certain design concerns exist regarding ease of use and legal liability. Therefore, most consumers in the United States will encounter ACC before CWS.

\section{Proximity Sensors and Obstacle Avoidance}

One technology that is particularly attractive to drivers who have limited neck motion is the parking aid. Parking aids include rear proximity sensors and other parking collision avoidance systems. ${ }^{41}$ These systems typically use audible alerts or iconic displays on the dashboard to indicate that the driver is about to back into an object. Anecdotal evidence also shows that these systems reduce the use of mirrors and direct visual inspection among the general public, which is further complicated by the rather poor performance of some of these systems. ${ }^{42}$ Nevertheless, rear camera systems are becoming increasingly common. More recently, automated parallel parking and docking alongside curbs ${ }^{43}$ is becoming a market reality; drivers can now purchase a semi-autonomous parallel parking option for certain vehicles.

\section{Driving Behavior and Feedback}

Opportunities also exist to observe driver behavior and provide feedback. This system is already being done in fleet vehicles ${ }^{44}$ and is starting to be used by the regular public. This monitoring and coaching is a delicate process; drivers may consider the loss of privacy to outweigh the benefits. Systems with poor user interaction models run the risk of being perceived as a nuisance. Research in drowsy-driver monitoring ${ }^{45}$ suggests that driver coaching systems that use a "trusted advisor" interaction model can provide effective information in a manner that drivers will accept. Research on this that is specific to drivers with disabilities is underway. ${ }^{46}$ Current technologies, such as OnStar, provide a means for drivers in need to obtain remote road assistance. This type of direct communication can be especially helpful to individuals who have disabilities who are in need of emergency assistance.

\section{THE FUTURE IN PERSONALTRANSPORTATION Paradigm Shift}

Two major technologic paradigm shifts will occur in the foreseeable future. First, the automotive industry is starting to see market penetration by intelligent transportation systems (ITS). A decade ago, experts believed it would be possible to move directly from vehicles operated by humans to fully automated vehicles. After initial successes, ${ }^{47,48}$ it became clear that the technical, institutional, and societal barriers are too difficult to overcome all at once. Instead, an incremental approach became the new paradigm, and the incorporation of new vehicle capability is occurring at the component level. ITS has steadily evolved from research prototypes to successful commercial products. Examples include automatic crash notification, collision warning and avoidance, lane-keeping assistance, vision enhancement systems, driver monitoring, and in-vehicle navigation systems.

The Defense Advanced Research Projects Agency (DARPA) Urban Grand Challenge ${ }^{49}$ showed that automated driving in non-highway settings is considerably closer to reality, thus prompting renewed calls for more rapid progress toward fully 
automated cars. ${ }^{50}$ This, of course, would provide significant value to drivers who have significant disabilities.

The second major technologic paradigm shift is in response to the aging of the population, which is leading to a greater awareness within the automotive industry that improvements must be made in various areas. ${ }^{51}$ The industry is also interested in quicker production cycles and reusable components. A component designed to support the needs of older drivers in one model line may also be used in a model line targeted at younger drivers. These factors combine to present incentives to embrace universal design, and this is supported by a recent "wish list" of research initiatives, applications, and system changes presented by the American Medical Association, which includes a call for improvements in vehicle design on this function: "Age-related changes in vision, cognition, and motor ability may affect an individual's ability to enter/egress a motor vehicle with ease... We encourage vehicle manufacturers to explore and implement enhancements in vehicle design that address and compensate for these physiologic changes"52

ITS and the trend toward reusable components are fundamentally changing the way cars work. Multifunction displays on the dashboard are now common, and factoryinstalled drive-by-wire is on the horizon. Vehicles are already on the market with no mechanical link between the accelerator and the engine. These trends provide key opportunities to reduce the cost of vehicle modification through standardized communication protocols. ${ }^{53-55}$

The research community has already started merging adaptive driving with ITS. For example, drive-by-wire products designed for the vehicle modification market were used by competitors in DARPA's recent automated vehicle competitions. ${ }^{56}$

Universal design is a system design approach that can minimize the cost of conversion vans. Vehicles designed for a wide range of users who have (or do not have) disabilities will provide easier means for modification. For example, some van companies are introducing vans that feature low floors in their base models. This low floor design allows for easy conversion for someone who uses a wheelchair and needs a lift or ramp.

Finally, the cost of modified vans and equipment range between $\$ 200$ and $\$ 90,000$ for a fully equipped vehicle. These adaptation costs are normally absorbed by thirdparty payers, such as insurance or State offices of Vocational Rehabilitation. Alternative funding sources (for individuals that may not work) also exist to get driving systems paid. Examples of these would be Workers Compensation Fund, The National Center for Victims of Crime, and the Department of Aging. Some nongovernment organizations also provide assistance to persons who have disabilities, such as Make-a-Wish Foundation of America, Polio Survivors Association, church groups, and private fundraisers.

\section{SUMMARY}

To ride safely in a vehicle, disabled drivers must use adaptive equipment and technology that is specific to their functional abilities. Furthermore, to minimize passenger and driver injury and damage from driving controls in the case of an accident, they must wear a well-positioned shoulder and lap belt that they can independently secure. For individuals who ride while seated in their wheelchair (and for unoccupied wheelchairs), the wheelchair must be safely secured to the vehicle floor during transportation to maintain a safe distance to driving controls during the ride and to ensure the wheelchair does not move during vehicle maneuvers. 
Several aspects of driving and preparing for driving can cause a disabled driver discomfort or present unsafe conditions. These instances include difficulty boarding or exiting the vehicle; maneuvering inside the vehicle into the driver area; securing the wheelchair in the docking system; positioning, securing, or releasing the seatbelt; wearing the seatbelt; reaching or using the primary and secondary controls; and loss of balance while making a turn. A CDRS and NMEDA equipment dealer must be consulted to help adjust controls, replace components, and select alternative devices that meet the user's needs. Although personal vehicles may soon be standard equipped with drive-by-wire controls and safety information systems to enhance safe driving for all, communication among drivers and passengers, a CDRS evaluator, and a NMEDA equipment dealer remain key in assuring the safety and independence of individuals who have disabilities when riding motor vehicles.

\section{REFERENCES}

1. Edsworth R. Class conflict and cultural consensus: the making of a mass consumer society in Flint Michigan. New Brunswick, NJ: Rutgers University Press; 1987.

2. Schieber F. Beyond TRB 218: Older driver research since 1988 [report]. Transportation Research Board 1999.

3. Office of Highway Policy Information. Highway statistics 2000. Available at: http:// www.fhwa.dot.gov/ohim/hs00. Accessed August 20, 2009.

4. US Census Bureau. Census 2000 gateway. Available at: http://www.census.gov/ main/www/cen2000.html. Accessed February 25, 2009.

5. LaPlante MP. Demographics of wheeled mobility device users. In: Space requirements for wheeled mobility [workshop]. Center for Inclusive Design and Environmental Access. Buffalo, New York, October 9-11, 2003.

6. Americans with Disabilities Act of 1990 (PL 101-336), 104 United States Statutes at Large. Washington, DC: Government Printing Office; 1990. p. 327-8.

7. RTC: Rural. Ruralfacts: inequities in rural transportation. Available at: http://rtc. ruralinstitute.umt.edu/Trn/TrnInequitiesFact.htm. Accessed March 20, 2008.

8. Chaves E, Boninger M, Cooper R, et al. Assessing the influence of wheelchair technology on perception of participation in spinal cord injury. Arch Phys Med Rehabil 2004;85(11):1854-8.

9. Gray D, Hollingsworth H, Stark S, et al. Participation survey/mobility: psychometric properties of a measure of participation for people with mobility impairments and limitations. Arch Phys Med Rehabil 2006;87(2):189-97.

10. Harvard $A B$. Disabilities and their implications for driving. Long Beach, $(C A)$ : NMEDA; 2006.

11. DeVivo MJ, Go BK, Jackson AB. Overview of the national spinal cord injury statistical center database. J Spinal Cord Med 2002, Winter;25(4):335-8.

12. National Mobility Equipment Dealers Association. National Mobility Equipment Dealers Association Guidelines. Available at: http://www.nmeda.org/members/ members-pdfs/nmeda_guidelines.pdf. Accessed August 4, 2009.

13. Davidoff GN, Roth EJ, Richards JS. Cognitive deficits in spinal cord injury: epidemiology and outcome. Arch Phys Med Rehabil 1992;72:275-84.

14. Association of Driver Rehabilitation Specialists. Available at: http://www.driver-ed. org/i4a/pages/index.cfm?pageid=1. Accessed August 4, 2009.

15. Simoes NF, Lindblom L. Driving with a spinal cord disorder. In: Lin VW, Cardenas DD, Cutter NC, et al, editors. Spinal cord medicine: principles and practice. 1st edition. New York: Demos Medical Publishing; 2003. p. 723-31. 
16. French D, Hanson CS. Survey of driver rehabilitation programs. Am J Occup Ther 1999;53(4):394-7.

17. Department of Transportation. FMVSS 403: platform lift systems for motor vehicles. Available at: http://www.carsafetylawyer.com/resources/federal-motorvehicle-safety-standards-fmvss. Accessed August 4, 2009.

18. Department of Transportation. FMVSS 404: platform lift installations in motor vehicles. Available at: http://www.carsafetylawyer.com/resources/federal-motor-vehiclesafety-standards-fmvss. Accessed August 4, 2009.

19. Society of Automotive Engineers. SAE J2388: secondary control modifications. Warrendale (PA): Society of Automotive Engineers; 2002.

20. Department of Transportation. FMVSS 207: seating systems. Available at: http://www.carsafetylawyer.com/resources/federal-motor-vehicle-safety-standardsfmvss. Accessed August 4, 2009.

21. van Roosmalen L, de Jongh I, Ritchie N, et al. Safety system and usability issues for wheelchair-seated drivers and passengers of private vehicles: a pilot study. In: RESNA annual conference. Washington, DC, June 29, 2008.

22. van Roosmalen, Lane LA. Driving with a disability-clinical and technical perspectives. In: International Seating Symposium. Orlando, FL, March 12, 2009.

23. RESNA. RESNA WC-4: 2009, Section 19: wheelchairs used as seats in motor vehicles-draft. Arlington, VA: American National Standards Institute (ANSI)/ Rehabilitation Engineering Society of North America (RESNA); 2009.

24. RESNA. RESNA WC-4: 2009, Section 20: wheelchair seating systems for use in motor vehicles-draft. Arlington, VA: American National Standards Institute (ANSI)/Rehabilitation Engineering Society of North America (RESNA); 2009.

25. Society of Automotive Engineers. SAE J2249: wheelchair tiedowns and occupant restraint systems — surface vehicle recommended practice. Warrendale, PA: SAE; 1999.

26. International Standards Organization. ISO/DIS 10542-1: wheelchair tiedowns and occupant restraint systems: part 1-requirements and test methods. Geneva, Switzerland: International Standards Organization; 2001.

27. van Roosmalen $L$. Wheelchair integrated occupant restraint system feasibility in frontal impact. Rehabilitation Science and Technology. Pittsburgh, PA: University of Pittsburgh; 2001.

28. van Roosmalen L, Bertocci GE, Karg P, et al. Belt fit evaluation of fixed vehicle mounted shoulder restraint anchors across mixed occupant populations. RESNA annual conference. Minneapolis, MN: RESNA Press; June 26, 1998.

29. van Roosmalen $L$, de Jongh I. Potential solutions to improve the safety of wheelchair seated drivers and passengers in private vehicles. Baltimore, MD: IASTED; 2008.

30. Bertocci GE, Souza AL, Szobota S. The effects of wheelchair-seating stiffness and energy absorption on occupant frontal impact kinematics and submarining risk using computer simulation. J Rehabil Res Dev 2003;40(2):125-30.

31. Adomeit D, Heger A, SAE International Web site. Motion sequence criteria and design proposals for restraint devices in order to avoid unfavorable biomechanic conditions and submarining. Available at: http://www.sae.org/technical/papers/ 751146. Accessed August 3, 2009.

32. States JD, Balcerak JC, Williams JS, et al. SAE International Web site. Injury frequency and head restraint effectiveness in rear-end impact accidents. Available at: http://www.sae.org/technical/papers/720967. Accessed August 3, 2009.

33. Svensson MY, Lovsund $P$, Haland $Y$, et al. SAE International Web site. Rear-end collisions-a study of the influence of backrest properties on head-neck motion 
using a new dummy neck. Available at: http://www.sae.org/technical/papers/ 930343. Accessed August 3, 2009.

34. Maher J. Report investigating the importance of head restraint positioning in reducing neck injury in rear impact. Accid Anal Prev 2000;32:299-305.

35. Fuhrman S. Pediatric wheelchair and headrest design guidelines and the effect of headrests on relative injury risk under rear impact conditions [dissertation]. Pittsburgh, PA: University of Pittsburgh; 2008.

36. Fuhrman S, Karg P, Bertocci G. Effect of wheelchair headrest use on pediatric head and neck injury risk outcomes during rear impact. Accid Anal Prev 2008; 40(4):1595-603.

37. Karg P, Sprigle S. Development of test methodologies for determining the safety of wheelchair headrest systems during vehicle transport. Development 1996; 33(3):290-304.

38. RERC on Wheelchair Transportation Safety. Guidelines for use of secondary postural support devices by wheelchair users during travel in motor vehicles. Pittsburgh, (PA): Rehabilitation Engineering Research Center on Wheelchair Transportation Safety; 2006.

39. Singh S. Driver attributes and rear-end crash involvement propensity [NHTSA report]. US Dept. of Transportation, National Highway Traffic Safety Administration, National Center for Statistics and Analysis, Advanced Research and Analysis. No. DOT HS 809 540. March 2003.

40. Steinfeld A, Duggins D, Gowdy J, et al. Development of the side component of the transit integrated collision warning system. Presented at the IEEE Intelligent Transportation Systems Conference. Washington, DC, October 3-6, 2004.

41. Ward N, Hirst S. An exploratory investigation of display information attributes of reverse/parking aids. International Journal of Vehicle Design 1998;19(1):41-9.

42. National Highway Traffic Safety Administration. Vehicle backover avoidance technology study, report to congress. Washington, DC: US Department of Transportation; 2006.

43. Langer D, Thorpe C. Range sensor based outdoor vehicle navigation, collision avoidance and parallel parking. Auton Robots 1995;2(2):147-61.

44. Eisenberg A. These back-seat drivers are moving up front. Available at: http://www.ny times.com/2007/02/04/business/yourmoney/04novel.html?scp=2\&sq=carchip\&st= cse. Accessed February 25, 2009.

45. Ayoob E, Steinfeld A, Grace R. Identification of an "appropriate" drowsy driver detection interface for commercial vehicle operations. Proceedings of the Human Factors and Ergonomics Society 47th Annual Meeting, Santa Monica, California, October 13-17, 2003. Santa Monica, California: Human Factors and Ergonomics Society; 2003.

46. Quality of Life Technology Center. DriveCap. Available at: http://www.cmu.edu/ qolt/Research/projects/drivecap.html. Accessed February 25, 2009.

47. Shlodover S. AHS Demo '97 "Complete Success." Available at: http://www.path. berkeley.edu/PATH/Intellimotion/intel63.pdf. Accessed August 3, 2009.

48. Thorpe C, Jochem T, Pomerleau D. The 1997 automated highway free agent demonstration. Available at: http://www.ri.cmu.edu/pub_files/pub2/thorpe_ charles_1997_2/thorpe_charles_1997_2.pdf. Accessed August 3, 2009.

49. Defense Advanced Research Projects Agency. Urban challenge. Available at: http://www.darpa.mil/grandchallenge. Accessed February 25, 2009.

50. Bunkley. GM to show a vehicle that drives by itself. Available at: http://www.ny times.com/2008/01/07/automobiles/07auto.html?_r=1. Accessed February 25, 2009. 
51. Waller P. The older driver. Hum Factors 1991;33(5):499-505.

52. Wang CC, Konsinski CJ, Schwartzberg JG, et al. Physician's guide to assessing and counseling older drivers. Available at: http://www.nhtsa.dot.gov/people/ injury/olddrive/physician_guide/PhysiciansGuide.pdf. Accessed August 3, 2009.

53. Steinfeld A. Accessibility and intelligent transportation systems. U.S. Department of Education, Interagency Committee on Disability Research (ICDR). Washington, DC, July 22, 2006.

54. Steinfeld A. Smart systems in personal transportation. In: Helal A, Mokhtari M, Abdulrazak B, editors. Technology for aging, disability, and independence (Volume II):computing and engineering design and applications. Hoboken, (NJ): John Wiley \& Sons; 2008.

55. Steinfeld A, Steinfeld E. Universal design in automobiles. In: Preiser WFE, Ostroff E, editors. Universal design handbook. New York: McGraw-Hill; 2001.

56. Olsen S. The pit crews behind DARPA's robot race. Available at: http://news. cnet.com/The-pit-crews-behind-DARPAs-robot-race/2100-11389_3-6188813.html. Accessed February 25, 2009. 